\title{
Discussion on the Determination of "Risk" in Preventive Environment Public Interest Litigation
}

\author{
Hongmei Zhang ${ }^{1, *}$ \\ ${ }^{1}$ Institute of Advanced Studies in Humanities and Social Sciences, Beijing Normal University at Zhuhai, Zhuhai, \\ Guangdong 519087, China \\ *Corresponding author. Email: greenriver2012@sina.com
}

\begin{abstract}
The ideal form of environment public interest litigation is preventive litigation. In order to overcome obstacles in judicial practice, environment public interest litigation should be divided into two different forms of litigation including danger defense litigation and risk prevention litigation based on different levels of risk. The determination of risks in preventive environment public interest litigation must be related to the future. The core of danger defense litigation is to provide people with the basis of choice with the help of science and technology or past experience, and the determination of risks should follow the technical specification approach; risk provides a means of behavior and decision-making, and risk prevention litigation aims to control the decisionmaking method of risk. Therefore, the determination of risks should follow the procedural control approach.
\end{abstract}

\section{Keywords: Danger defense, Risk prevention, Technological approach, Procedural control.}

\section{INTRODUCTION}

Preventive environment public interest litigation is of great significance for preventing environmental risks and achieving the goal of ecological protection. However, due to the lack of a unified "risk" judicial determination standard, it has been left in the cold in judicial practice and has also brought obstacles to the further development of environment public interest litigation. Therefore, it is very important to clarify the risk determination path and improve the risk determination standards.

\section{LITERATURE REVIEW}

Risk is becoming more and more common and widespread in the current era. As an expression of concerns about the future, risk has also brought about a change in people's perceptions, that is, "making the present serve the future". This concept pointing to the future has a significant impact on legal theory. It has changed from a backwardlooking concern about risks that have actually occurred (reflected in attribution and relief) to a forward-looking concern about risks that have not yet actually occurred (mainly prediction and prevention). [1] Risk is closely related to prevention. As a typical field of risk society, environmental issues determine the importance of prevention in the environmental field, and prevention has become the basic idea and primary principle of environmental law. Therefore, based on the theory of risk society, legislation, law enforcement, and justice are all undergoing a profound change, that is, from remedying damage to regulating and preventing risks. Preventing risks has become an important value orientation of the law, and especially for the issues of irreversible environmental damage, people should take precautions. In environmental justice, "taking preventive measures" has become an inevitable choice for environmental litigation to deal with risks, and environmental litigation has changed from a relief model to a prevention model. [2] In theory, many scholars such as Professor Wang Jin [3] and Professor Xiao Jianguo [4] recognized the preventive function of environment public interest litigation and introduced the concept of preventive litigation from administrative law. [5] However, the current judicial practice of environment public interest litigation in China has a certain lag and it is still a relief environment public interest litigation [6]. The reason is that the initiation of preventive environmental public interest lawsuits doesn't 
require substantial damage, and it can be litigated as long as there is a threat of ecological damage or a risk of damage. However, when no substantial damage has been caused, the current legislation and related judicial interpretations lack clear and uniform standards on how to determine whether the behavior of environmental pollution or ecological damage has the risk of causing damage to the public interest, and as a result, preventive environment public interest litigation is left in the cold in judicial practice. In 2019, Professor Yu Wenxuan studied the judicial determination of "significant risks" in environmental civil litigation, and proposed countermeasures to improve the judicial determination standards of "significant risks". [7] Another important reason for the various dilemmas of preventive environment public interest litigation in judicial practice is that risks have different levels and it is difficult to apply a unified risk determination standard. Therefore, only by distinguishing different forms of environment public interest litigation based on different levels of risk, and clarifying different risk determination paths and determination standards, can the true needs of judicial practice be met.

\section{THE MAIN FORMS OF PREVENTIVE ENVIRONMENT PUBLIC INTEREST LITIGATION}

Preventive environment public interest litigation is a lawsuit filed for damage that has not actually occurred. According to the degree of possibility of damage, that is, the degree of risk, damage that has not yet occurred can be divided into danger and risk. Danger means that there is a very high probability that it will cause specific and actual harm, which will be transformed into actual damage if it is not defended. The basic feature of risk is uncertainty. Certainty and uncertainty are actually aimed at the causal relationship between human activity and damage. Risks are both realistic and unrealistic. According to the German scholar Breuer's tripartite theory of danger, risk and residual risk, the danger should be eliminated and defended, the risk should be prevented and avoided, and the residual risk must be tolerated. [8] Therefore, preventive environment public interest litigation can be divided into two different forms of litigation: danger defense litigation and risk prevention litigation.

\subsection{Danger Defense Environment Public Interest Litigation}

"Danger" originated from the concept in police law and order law, and later extended to the field of environmental law, which refers to the "clear and significant" hazards in specific cases, that is, specific dangers. Danger defense refers to the elimination of threats that damage the environment, human body, and property right and interests to prevent the actual occurrence of damage. Danger defense environment public interest litigation refers to the public interest litigation filed against the illegal activities of the government and polluters with the goal of danger defense. In danger defense environment litigation, the judgment of danger is a kind of prediction or assessment of damage, and the causal relationship of damage has been recognized. On the one hand, the occurrence of damage is required to have cover degree and probability; on the other hand, the judgment of predictive causality must be based on scientific evidence or empirical rules, which should be deducible and verifiable. In Chinese judicial practice, the Acer Pentaphyllum Diels Protection Case and the Green Peacock Habitat Protection Case are two representative preventive environmental public interest litigations. Both plaintiffs' litigation goals are to eliminate the ecological environment risks that have not yet occurred but are highly probable, and both the defendants are required to assume preventive relief responsibilities. In the Acer Pentaphyllum Diels Protection Case, the plaintiff stated that "It can be accurately foreseen that after the normal storage of the power station reservoir, ... poses a serious threat to the survival of Acer pentaphyllum Diels. In the Green Peacock Habitat Protection Case, the plaintiff believed that "The project itself poses a major threat to the survival of the green peacock" and the defendant should eliminate the danger. Both of the two preventive environmental public interest lawsuits are aimed at potential risks, and the damage has not yet occurred. Therefore, the focus of the dispute in the case is on how the plaintiff's "serious threat" and "major threat" should be identified.

\subsection{Risk Prevention Environment Public Interest Litigation}

The risks here mainly refer to uncertain environmental risks. Therefore, the risk prevention environment public interest litigation refers to a lawsuit against an act that violates or hinders the realization of the risk prevention function, which 
mainly includes the inaction of the government and actions by polluters that pose significant risks. For example, public interest litigation brought by the government as the defendant because the government is lazy to take measures to handle with climate change is a risk prevention environment public interest litigation. China currently doesn't have such a form of environment public interest litigation practice, but the practice of promoting risk prevention environment public interest litigation in China is of great significance. Because in the context of risk society, the generation of national environmental risk prevention tasks promotes the transformation of environmental governance from hazard prevention to risk prevention. And the risk prevention environment public interest litigation can promote the formulation and implementation of risk prevention policies with its policy functions, effectively promoting the practice of risk governance, and promoting the transformation of traditional environmental governance models.

\section{PATHS FOR DETERMINING "RISKS" IN PREVENTIVE ENVIRONMENT PUBLIC INTEREST LITIGATION}

It can be seen from the above that according to the possibility of damage, it can be divided into different levels of danger, risk and residual risk. For danger, the occurrence of its damage is highly probable and must be eliminated; for risks, the occurrence of its damage is uncertain, but once it occurs, the consequences of damage are extremely serious, irreversible and unrecoverable. Therefore, risks must be dealt with and avoided. The residual risk is what society must tolerate and allow. Therefore, based on the different characteristics of hazards and risks and the different responses of laws to them, the corresponding determination standards and determination paths should also be different.

\subsection{Technical Specification Approach}

In the danger defense environment public interest litigation, the technical specification approach should be followed, and science and technology or experience should be used to predict, analyze and evaluate the damage results, so as to determine the existence of "danger". Danger is a form of risk, and the remedy for it is to eliminate it, that is, to "eliminate the danger". Therefore, it is required that the possibility of its damage has reached a level that can't be tolerated by the legal order. For example, in the Acer Pentaphyllum Diels Protection Case and the Green Peacock Habitat Protection Case, the accused behavior will pose a serious threat to the survival of the population before the existence of "danger" can be determined. At the same time, there must be a causal relationship between the threat of damage and the accused behavior. The threat of damage is a perception of danger, which means that the occurrence of damage is predictable and will occur if preventive measures are not taken. Because this threat of damage is a deterministic damage and predictable danger, it can be determined through the approach of technical specification, specifically referring to the determination of the threat of damage and causality based on scientific evidence or empirical rules. Scientific evidence refers to the results of technical prediction, analysis and evaluation based on risk assessment methods, and it is a "statement of certainty". The use of empirical rules is to use past experience to make predictions and form a certainty. In judicial practice, the understanding and inquiries about the living environment, reproduction breeding, field habits, population characteristics and other professional knowledge of Acer pentaphyllum Diels in the Acer Pentaphyllum Diels Protection Case and the key impact of environmental impact assessment in the Green Peacock Habitat Protection Case resort to science and technology or empirical rules to identify "danger" based on the results of evaluation and prediction.

\subsection{Procedural Control Approach}

In risk prevention environment public interest litigation, it mainly deals with the problem of uncertainty. Specifically, the probability of damage occurrence is unknown, and there is a lack of scientifically sufficient evidence to prove the damage occurrence, but the possibility of damage occurrence can't be excluded, which is scientifically suspicious. Therefore, the determination of risks can't be based on the assessment results. There are limitations in science and technology, and even science is one of the causes of risks, which means that the past experience can't provide help. Therefore, the determination path of the risk can only depend on the legal approach to the risk. Because of risks, the law should actively take preventive and protective measures to respond to and avoid risks. 
Both Baker and Giddens pointed out that risks are man-made risks, and the occurrence of damage may not have been foreseen, but this doesn't change the fact that they are the effects of human decisionmaking. Therefore, risk is related to decisionmaking, and risk response is also closely related to decision-making. Compared with the decisionmaking of "danger", expert-led decision-making has changed, and more attention is paid to the public's response to risk in decision-making. This is consistent with Baker's claim that risk is both a scientific construction and a social construction. The definition of risk should break the monopoly of scientific rationality, emphasize the interaction between scientific rationality and social rationality, resolve decision-making risks with procedural rationality, promote risk prevention with ecological democracy, and emphasize that a deliberative democracy with public participation is the best procedural model for dealing with risks.

Therefore, the determination of risks is no longer an assessment based on the results, but a review of the decision-making procedures. The deliberative democratic process unites different groups to promote the generation of "public values" and serves as the basis for decision-making. The response and avoidance of risks lies in the decisionmaking process rather than in the results. Therefore, the determination of risk doesn't lie in the technical analysis of possible risks and results, but in a form of thinking, which is embodied in the procedure of decision-making, and the determination path is correspondingly a procedural control approach. In case of disputes arising from nuclear energy utilization technology or genetic technology, the existence of major risks should be determined based on whether it conforms to the procedural model of risk decision-making.

\section{CONCLUSION}

In conclusion, according to the tripartite theory of danger, risk, and residual risk, the law has adopted different approaches to deal with it. Corresponding preventive environment public interest litigation is manifested in two different litigation forms, namely, danger defense litigation and risk prevention litigation, which determine the different paths of judicial determination of risks. Danger is a prediction of the possible state of future development based on recognized facts, objective experience and reason rules. It is based on predictive causality and determines that the damage is highly likely to occur. Therefore, the determination of dangers follows the path of technical specification and should be based on a fairly confident prediction of future development. The uncertainty of risk determines the limitations of science and technology in risk determination. At the same time, the response to risks requires active prevention rather than veto actions, and it seeks solutions to problems, that is, the procedural model of deliberative democracy. Therefore, in the risk prevention environment public interest litigation, the determination of risks is to follow the procedural control approach and determine the existence of major risks according to whether the decision-making control procedure is violated.

\section{AUTHORS' CONTRIBUTIONS}

This paper is independently completed by Hongmei Zhang.

\section{REFERENCES}

[1] [English] Jenny Steele. Risks and Legal Theory, Beijing: China University of Political Science and Law Press, 2012. (in Chinese)

[2] Zhang Xudong. Reflections on the Rules of Preventive Environment Civil Public Interest Litigation Procedures, "Science of Law" (Journal of Northwest University of Politics and Law), Issue 4, 2017. (in Chinese)

[3] Wang Jin. Environmental Law, Beijing: Peking University Press, 2014. (in Chinese)

[4] Xiao Jianguo. Research on Basic Issues of Environment Public Interest Litigation, National Judges College Law Journal, Issue 4, 2014. (in Chinese)

[5] Zuo Yaluo. The Functional Boundaries of the Two Major Public Interest Litigations and Their Role in Chinese Social Governance, Journal of Yunnan University, Law Edition, Issue 6, 2015. (in Chinese)

[6] Wu Kaijie. On Preventive Environment Public Interest Litigation, Theory and Reform, Issue 3, 2017. (in Chinese)

[7] Yu Wenxuan, Mou Tong. On the Judicial Determination of "Major Risks" in Environmental Civil Litigation, National Judges College Law Journal, Issue 14, 2019. (in Chinese)

[8] Zhang Bao. From Hazard Prevention to Risk Prevention: Risk Turning and System Adjustment in Environmental Governance, Legal Forum, Issue 1, 2020. (in Chinese) 